\title{
Improving total-building seismic performance using linear fluid viscous dampers
}

\author{
Giuseppe Marcantonio Del Gobbo ${ }^{1}$ (D) Anthony Blakeborough ${ }^{1} \cdot$ \\ Martin S. Williams ${ }^{1}$
}

Received: 20 November 2017/ Accepted: 22 February 2018/Published online: 2 March 2018

(C) The Author(s) 2018. This article is an open access publication

\begin{abstract}
Previous research has revealed that Eurocode-compliant structures can experience structural and nonstructural damage during earthquakes. Retrofitting buildings with fluid viscous dampers (FVDs) can improve interstorey drifts and floor accelerations, two structural parameters that characterize seismic demand. Previous research focusing on FVD applications for improving seismic performance has focused on structural performance. Structural parameters such as interstorey drifts and floor accelerations are often evaluated. Complexities arise as these parameters are often competing objectives. Other studies use damage indices that are influenced by several assumptions to represent performance. The use of repair costs is a more appropriate measure of total-building seismic performance, and avoids these limitations. This study investigates the application of linear FVDs to improve total-building seismic performance considering repair costs. The energybased method commonly used to calculate damper coefficients is modified to improve its accuracy. The optimal amount of damping with respect to repair costs (estimated using the FEMA P-58 procedure) is identified as $25-45 \%$. This contrasts with a previously suggested optimal damping of $20-25 \%$, based on structural parameters, that is frequently targeted. This study on the damping-repair cost relationship provides insight when selecting levels of damping for structural designs and retrofits. It also highlights that retrofit methods may be enhanced by using repair costs, rather than structural parameters. The FVD buildings significantly reduce both drift-sensitive and acceleration-sensitive damage. Structural damage is also negligible in the FVD buildings: a major step towards achieving building serviceability following an ultimate limit state level earthquake.
\end{abstract}

Giuseppe Marcantonio Del Gobbo

giuseppe.delgobbo@eng.ox.ac.uk

Anthony Blakeborough

tony.blakeborough@eng.ox.ac.uk

Martin S. Williams

martin.williams@eng.ox.ac.uk

1 Department of Engineering Science, University of Oxford, Parks Road, Oxford OX1 3PJ, UK 
Keywords Fluid viscous dampers · FEMA P-58 - Concentric braced frames · Nonstructural systems · Damping

\section{Introduction}

Previous research has revealed that concentric braced frame (CBF) structures designed using the Eurocode (CEN 2010a) can experience structural and nonstructural damage during earthquakes. Achieving a desired seismic performance requires the coordination of structural and nonstructural performance. FEMA P-58 (FEMA 2012a) analyses conducted by Del Gobbo et al. (2017, 2018) revealed that Eurocode-compliant CBF structures are likely to experience extensive damage during both ultimate limit state (ULS) and serviceability limit state (SLS) earthquakes. The ULS earthquake, or no-collapse requirement in Eurocode 8 (CEN 2013), has a 10\% probability of exceedance in 50 years. Structures are designed to withstand the ULS design seismic action while retaining structural integrity after the earthquake. The SLS earthquake, or damage limitation requirement in Eurocode 8 , has a $10 \%$ probability of exceedance in 10 years. Damage at the SLS should be limited to a point that does not compromise building serviceability (CEN 2013). Interstorey drifts and floor accelerations were the main structural parameters that characterized seismic demand.

Retrofitting buildings with supplemental damping devices can substantially reduce drifts and improve the seismic performance of buildings. FVDs have been identified as the most promising of these devices for nonstructural considerations as they can improve both drifts and floor accelerations, unlike hysteretic devices (Mayes and Wassim 2005; Astrella and Whittaker 2005; Christopoulos and Filiatrault 2006; Vargas and Bruneau 2006, 2007; Pavlou and Constantinou 2006; Dicleli and Mehta 2007; Wanitkorkul and Filiatrault 2008). This paper presents an investigation on the application of FVDs to minimize structural and nonstructural damage.

Despite having the potential to be effective and economically viable solutions, research focusing on FVD applications for improving nonstructural seismic performance has been limited. (1) Previous research on the use of FVDs has focused on structural performance, while nonstructural performance is often not considered. (2) Structural parameters such as interstorey drifts and floor accelerations are often evaluated. Complexities arise as these parameters are often competing objectives. Limitations are introduced when determining appropriate parameter weights to represent performance. Other studies use damage indices that are influenced by several assumptions to represent performance. Our use of repair costs is a more appropriate measure of total-building seismic performance and avoids these limitations. (3) The optimal amount of damping with respect to repair costs has not been investigated. (4) There is also a need to clarify what seismic performance improvements can and cannot be achieved using supplemental damping.

Four-, eight- and 16-storey Eurocode-compliant designs are retrofitted with linear FVDs. The energy-based method commonly used to calculate damper coefficients for linear FVDs is evaluated and modified to improve its accuracy. The optimal amount of damping with respect to repair costs is investigated using the FEMA P-58 procedure (FEMA 2012b). The seismic performance of the FVD-retrofitted buildings is evaluated and limitations of FVD performance improvements are identified.

The FEMA P-58 procedure (FEMA 2012b) allows for building-specific seismic losses to be calculated. One of the first loss estimation methods, referred to as assembly-based vulnerability, was proposed by Porter and Kiremidjian (2001). In this method, the entire 
building is considered as a collection of individual components. Fragility functions are used to determine the expected damage to individual components, while unit cost functions determine the corresponding repair costs. The total building repair cost can be calculated from the sum of the individual component damages.

The assembly-based vulnerability concept was integrated into the FEMA P-58 performance assessment procedure (FEMA 2012b). The procedure has been used to conduct comparative studies. Mayes et al. (2013) used the FEMA P-58 procedure to evaluate six alternative structural systems including a FVD design. Terzic et al. (2014) conducted a lifecycle cost analysis of five structural designs for a three-storey office building. A structure with FVDs was included. Jarrett et al. (2015) presented two new structural systems and compared the seismic performance to traditional systems using FEMA P-58.

This paper is the first to perform a detailed economic seismic loss estimation study on braced steel frames with viscous dampers. It is the first study to investigate optimal damping using repair costs and the FEMA P-58 procedure. As a result, the scope of this paper is limited to linear FVDs. Nonlinear FVDs are often used in practice, and an obvious extension would be to consider nonlinear dampers.

\section{Methods}

The method adopted in this paper comprises the following steps, described more fully below: design of a suite of Eurocode-compliant steel CBF buildings, nonlinear modelling of the structures using OpenSees (McKenna 2017), calculation of damping parameters, and implementation of the FEMA P-58 assessment procedure.

\subsection{Description of Eurocode buildings}

The suite of building designs used in this paper were taken from the Del Gobbo et al. (2018) study. The buildings are representative of structures designed using modern codes for regions with significant seismic hazard. The scope of the investigation is limited to steel CBF office buildings designed in accordance with the Eurocode standards CEN 2010a). Braced steel frames are a common design type and can also be used to accommodate dampers (Chen and Mahin 2012). 4-storey, 8-storey and 16-storey structures with storey heights of $3.5 \mathrm{~m}$ were designed.

The structures were designed to resist dead, imposed, snow, wind and seismic loads using the Eurocodes (CEN 2010a, b, c, 2013). Dead loads considered in the design include the self-weight of structural members as well as allowances for nonstructural components $\left(\mathrm{DL}=4.47 \mathrm{kN} / \mathrm{m}^{2}\right)$. The imposed loads correspond to office use (Category B1) with the intermediate partition load value ( $\mathrm{IL}=3.3 \mathrm{kN} / \mathrm{m}^{2}$ ). The Type One horizontal elastic response spectrum and medium sand (ground class $\mathrm{C}$ ) were used. A behavior factor of four was selected, corresponding to a ductility class medium frame. A peak ground acceleration of $0.306 \mathrm{~g}$ was selected for the building site (Solomos et al. 2008).

Two sets of building designs are considered: standard designs $(S)$ and advanced drift designs (D). Eurocode $8 \mathrm{Cl}$ 4.4.3 (CEN 2013) specifies damage limitation requirements as interstorey drift limits based on the composition of nonstructural systems in the building. The strictest drift limit "for buildings having non-structural elements of brittle materials" is $d_{r} v \leq 0.005 h$, where $d_{r}$ is the design interstorey drift, $h$ is the storey height and $v$ is a reduction factor ( 0.5 for Importance Class II) based on the lower return period of the 
damage limitation earthquake. Serviceability is expected at $0.5 \%$ drift according to the Eurocode methodology. One set of buildings was designed to meet the $0.5 \%$ drift criterion during the SLS, referred to as $4 \mathrm{~S}, 8 \mathrm{~S}$ and $16 \mathrm{~S}$ for the four-, eight-, and 16-storey structures respectively. These standard designs met the most stringent drift requirements of Eurocode-compliant structures.

A second set of buildings was designed to achieve beyond-code performance, while still applying the Eurocode approach. A four- and an eight-storey structure were designed to meet the Eurocode serviceability $0.5 \%$ drift criterion during the ULS earthquake, referred to as $4 \mathrm{D}$ and $8 \mathrm{D}$ respectively. The advanced drift criterion was unable to be met feasibly for the 16-storey building using CBFs; brace sections could not be selected to meet the $0.5 \%$ ULS drift limit and the Eurocode steel design requirements without placing them in an impractical number of bays. This exhibits the demanding requirements of the selected beyond-code performance methodology. Elevations of the structures are shown in Fig. 1. The locations of FVDs are indicated in red. Buildings 4D, 8S, 8D and $16 \mathrm{~S}$ have four braced bays in each direction. Building $4 \mathrm{~S}$ only required two braced bays in each direction to meet the drift limit. Plan views of the structures are shown in Fig. 2.

The structural system is composed of standard UK structural steel sections. The columns and bracing are sections are Grade S355, with a nominal yield stress of $355 \mathrm{MPa}$ (Tata Steel Europe Limited 2014). Full design information and section details are available in Del Gobbo et al. (2018).

\subsection{OpenSees modelling}

The buildings are modelled in OpenSees (McKenna 2017). Planar models were used to determine the response of the structures according to Eurocode $8 \mathrm{Cl} 4.2 .3$. Connections were defined as perfectly pinned or rigid. Rigid diaphragm constraints in the $x$ direction were imposed on all nodes of each floor using truss elements with a sufficiently large axial stiffness. Pinned beam-column and beam-beam connections are used. The columns are continuous over several storeys with rigid splices and are pinned at base level. Gravity columns and the corresponding P-Delta effects were idealized using a leaning column. Distributed plasticity force-based beam-column elements were used to model columns with Gauss-Lobatto integration and five integration points. Column sections were modelled using 12 fibers for major axis bending and 40 fibers for minor axis bending (Kostic and Filippou 2012). It was assumed that structural degradation would not play a significant role

(d)

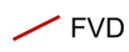

(a)

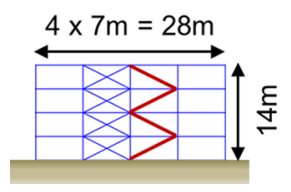

(c)

(b)

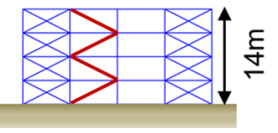

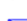

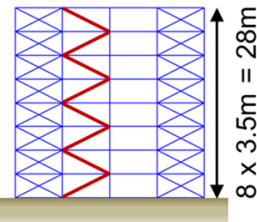

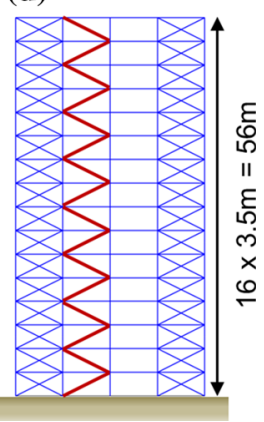

Fig. 1 Elevations of the office buildings with locations of FVDs. a 4S, b 4D, c 8S and 8D, d 16S 
(a)

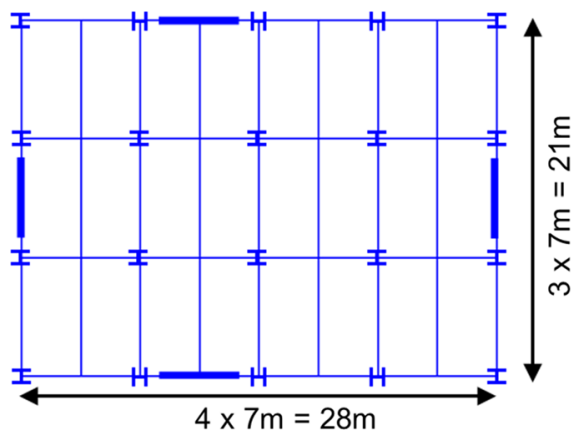

(b)

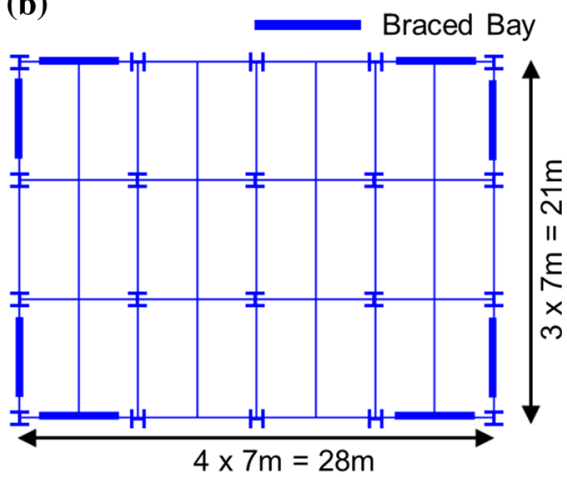

Fig. 2 Plan views of the office buildings. a 4S, $\mathbf{b}$ all other buildings

due to the intensities considered and the interstorey drifts that were observed. Although this is commonly done in literature, it should be noted that a study conducted by Tsitos et al. (2018) suggested that the consideration of degradation using plastic hinges can affect interstorey drift results at larger levels of demand.

The Uriz et al. (2008) physical-theory model was used to model brace members. Five fiber layers across the depth of each flange and along the web were used for the SHS brace sections. Two layers were used in the widths. The Menegotto-Pinto material was used with a yield stress of $355 \mathrm{MPa}$ and a strain-hardening ratio of 0.3\% (Uriz and Mahin 2008). Each brace was modelled using two elements with an initial imperfection of $0.1 \%$ at the midspan and three integration points. It was found that a fictitious force at the midspan developing $5 \%$ of the yield moment was necessary to prevent brace straightening (Uriz and Mahin 2008).

Dampers are modelled as linear viscous dashpots using the "twoNodeLink" element. The "Viscous" material was assigned to the damper elements. Inherent damping of 5\% was modelled using mass and tangent stiffness proportional Rayleigh damping. Although lower values are often used, the value of 5\% damping was selected to match the default for the Eurocode 8 horizontal response spectrum and is consistent with several previous studies (e.g. Charney 2008; D'Aniello et al. 2013; Karamanci and Lignos 2014). The use of Rayleigh damping and the selection of corresponding assumptions is the matter of much debate. Initial sensitivity studies of repair costs considering lower values of inherent damping or the use of initial stiffness for Rayleigh damping (Del Gobbo et al. 2018) found that total repair costs varied by less than 10\%. Tables 1 and 2 provide the periods and modal mass participation factors of the buildings, respectively.

Table 1 Periods of buildings

\begin{tabular}{llllll}
\hline Mode & $4 \mathrm{~S}(\mathrm{~s})$ & $8 \mathrm{~S}(\mathrm{~s})$ & $16 \mathrm{~S}(\mathrm{~s})$ & $4 \mathrm{D}(\mathrm{s})$ & $8 \mathrm{D}(\mathrm{s})$ \\
\hline 1 & 0.52 & 0.97 & 2.34 & 0.37 & 0.67 \\
2 & 0.20 & 0.32 & 0.67 & 0.14 & 0.22 \\
3 & 0.12 & 0.18 & 0.35 & 0.09 & 0.12 \\
\hline
\end{tabular}


Table 2 Modal mass participation factors

\begin{tabular}{lccccc}
\hline Mode & $4 \mathrm{~S}(\%)$ & $8 \mathrm{~S}(\%)$ & $16 \mathrm{~S}(\%)$ & $4 \mathrm{D}(\%)$ & $8 \mathrm{D}(\%)$ \\
\hline 1 & 80.7 & 75.0 & 65.2 & 80.7 & 74.2 \\
2 & 14.8 & 17.4 & 21.2 & 14.8 & 18.1 \\
3 & 3.2 & 4.2 & 6.3 & 3.1 & 4.5 \\
\hline
\end{tabular}

\subsection{Calculation of damping parameters}

\subsubsection{Required amount of damping}

Eurocode 8 (CEN 2013) and ASCE 7-10 (ASCE 2013) determine the total damping ratio $(\zeta)$ required to achieve a desired performance level through the use of damping correction factors. The damping correction factor $(\eta)$ is the ratio of a desired performance and the bare frame performance as presented in Eq. 1, where $P$ refers to some measure of seismic performance. The most commonly used measure of performance is maximum interstorey drift.

$$
\eta=\frac{P_{\text {damped }}}{P_{\text {bare }}}
$$

The required amount of damping can be determined given the desired damping correction factor. Eurocode 8 provides a relationship (Eq. 2 below) between the total damping ratio and the damping correction factor in Cl. 3.2.2.2 (CEN 2013), where damping is a percentage.

$$
\eta=\sqrt{\frac{10}{5+\zeta}} \geq 0.55
$$

ASCE 7-10 (ASCE 2013) presents the damping correction factor-damping ratio relationship in table format, a portion of which is reproduced in Table 3. Values are also provided for the damping correction factor calculated using Eurocode 8 . The factors from the two methods are comparable, with the main difference being the limit of $\eta \geq 0.55$ imposed on the Eurocode 8 equation.

Supplemental damping $\left(\zeta_{d}\right)$ is the total damping less the inherent damping. Once the required amount of supplemental damping is calculated, the damper coefficients and the associated damper placement that produce this level of damping can be determined.

Table 3 Damping ratios and corresponding damping correction factors

\begin{tabular}{lll}
\hline Total damping $(\%)$ & ASCE $1 / \eta$ & Eurocode $1 / \eta$ \\
\hline$\leq 2$ & 0.8 & 0.8 \\
5 & 1.0 & 1.0 \\
10 & 1.2 & 1.2 \\
20 & 1.5 & 1.6 \\
30 & 1.8 & - \\
40 & 2.1 & - \\
50 & 2.4 & - \\
\hline
\end{tabular}




\subsubsection{Calculation of damper coefficients}

This paper is limited to linear FVDs. The force output of a linear FVD is given by Eq. 3, where $F_{i}$ is the force, $C_{i}$ is the viscous damping coefficient and $\dot{u}_{r i}$ is the extensional velocity of damper $i$.

$$
F_{i}=C_{i} \dot{u}_{r i}
$$

Uniform damper placement was used, evenly distributing the supplemental damping between each storey. This technique is one of the most commonly used placement methods and often serves as a benchmark for evaluating alternative methods (Lopez Garcia and Soong 2002; Pavlou and Constantinou 2006; Hwang et al. 2013; Palermo et al. 2013; Landi et al. 2015; Dall'Asta et al. 2016). One damper is used per storey in this paper, resulting in the damping coefficient at each storey $j\left(C_{j}\right)=C_{i}$.

To size and place the dampers, the desired supplemental damping to be introduced by the FVDs must be converted to viscous damping coefficients. The energy method from Whittaker et al. (2003) is frequently used to perform this procedure. The energy method formula for linear FVDs is reproduced in Eq. 4, where $\zeta_{d, n}$ is the supplemental damping ratio in mode $n, \theta_{j}$ is the angle of damper inclination at storey $j, \phi_{r j}^{2}$ is the relative modal displacement, and $\phi_{i}$ is the modal displacement of mass $m_{i}$.

$$
\zeta_{d, n}=\frac{T_{n} \sum_{j} C_{j} \cos ^{2} \theta_{j} \phi_{r j}^{2}}{4 \pi \sum_{i} m_{i} \phi_{i}^{2}}
$$

The energy method formula produces an approximation of the supplemental damping, or an equivalent viscous damping ratio, by assuming vertical motions are insignificant (shear building), modes can be uncoupled, and linear structural behavior. Given the desired damping ratio and the damper distribution, the damper coefficients can be determined using the energy method.

\subsection{FEMA P-58 seismic performance assessment procedure}

The FEMA P-58 intensity-based nonlinear performance assessment procedure (FEMA 2012 b) was used to evaluate seismic performance of structures in terms of repair costs. The use of repair costs is an appropriate measure of total-building seismic performance that avoids the limitations of structural parameters and damage indices (Del Gobbo et al. 2018). Each building component susceptible to earthquake-induced damage has fragility and repair cost functions. Peak structural response parameters from nonlinear time history analyses representing earthquakes are used with fragility functions to determine probable damage states for the components. Repair cost functions then estimate the losses in dollars for each damage state.

Structural fragility groups and quantities were determined by the structural design. Nonstructural fragility groups and quantities were estimated using the median commercial office building quantities from the Normative Quantity Estimation Tool (FEMA 2012b). Robust equipment anchorage and seismic design category D for buildings with stringent seismic design were assumed to avoid overestimating repair costs. The FEMA P-58 setup used in the project is described in detail by Del Gobbo et al. (2018). Table 4 provides a summary of the critical fragility information used in the project. Peak floor acceleration (PFA) and interstorey drift ratio (IDR) are engineering demand parameters (EDPs), $x_{m}$ is 
Table 4 Summary of critical structural and nonstructural system fragility information

\begin{tabular}{lllll}
\hline System & EDP & Damage state & $x_{m}$ & $\beta$ \\
\hline Concentric braced frame & IDR & Brace buckling and yielding & 0.01 & 0.3 \\
& & Brace fracture or local buckling & 0.0178 & 0.3 \\
Glass curtain wall & IDR & Glass cracking & 0.01097 & 0.45 \\
& & Glass falls from frame & 0.01254 & 0.45 \\
Gypsum wall partition with metal studs & IDR & Minor cracking & 0.0021 & 0.6 \\
& & Moderate cracking or crushing & 0071 & 0.45 \\
& & Significant cracking or crushing & 0.012 & 0.45 \\
Suspended ceiling, vertical and lateral & PFA & Minor tiles dislodgement & $0.35 \mathrm{~g}$ & 0.4 \\
support & & Moderate tile dislodgement and grid & $0.55 \mathrm{~g}$ & 0.4 \\
& & damage & & \\
& & Total ceiling collapse & $0.8 \mathrm{~g}$ & 0.4 \\
Air handling unit & PFA & Equipment does not function & $0.25 \mathrm{~g}$ & 0.4 \\
Desktop electronics & PFA & Falls, does not function & $0.4 \mathrm{~g}$ & 0.5 \\
\hline
\end{tabular}

the median EDP value for the damage state, and $\beta$ is the standard deviation of the natural logarithms of the EDP values. Due to space constraints, only fragility functions that critically influence economic losses are provided. It is for this reason that velocity-sensitive components that are damaged by toppling, such as bookcases and filing cabinets, are not shown.

Buildings may be demolished following an earthquake due to high repair costs from issues such as large residual drifts. It has been found that owners often elect to demolish and replace the existing building if repair costs exceed $40 \%$ of the building cost (FEMA 2012b). This criterion for building demolition was checked for all analyses. Secondly, the CBF fragility functions are used. The structural analyses revealed that brace yielding and/ or buckling could take place, while the columns essentially remained elastic. As a result, any associated repair costs were captured and included in the calculation of total losses. Any large envelope drifts are reflected in the calculated repair costs.

Suites of ground motion representing the Eurocode 8 ULS and SLS earthquake intensities were taken from the Del Gobbo et al. (2018) study. Records were obtained from the PEER ground motion database (PEER 2013) using the Eurocode 8 response spectrum. A factor of 0.5 was used to define the SLS spectrum. The suite for each building and limit state consists of 25 ground motion records with the smallest mean squared error (MSE) between the ground motion spectrum and the target Eurocode spectrum over the period range of $0.2 T_{1}$ and $2 T_{1}$. The ULS and SLS spectra for the 4-storey standard structure are shown in Fig. 3.

\section{Modification of the energy method}

\subsection{Calculation of achieved damping}

The supplemental damping calculated by the energy method (Eq. 4) is an approximation. Occhiuzzi (2009) noted that only a small number of research papers calculate an estimate 
(a)

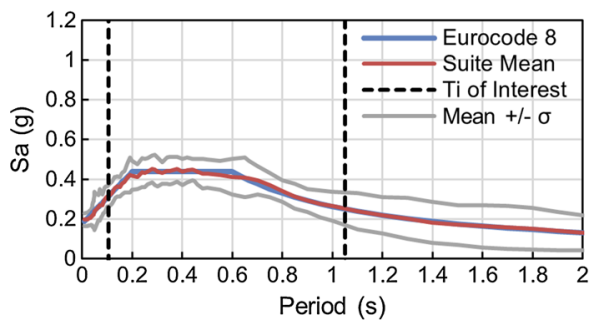

(b)

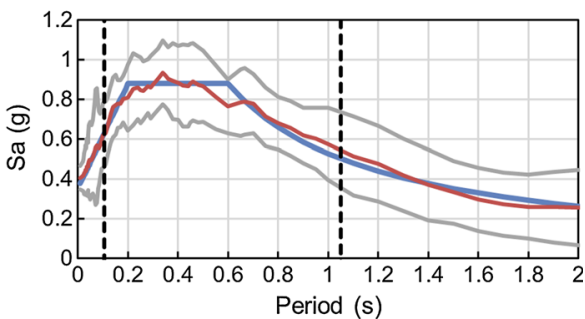

Fig. 3 Comparison of the $4 \mathrm{~S}$ ground motion suite spectra and the Eurocode 8 spectra. a SLS spectra, b ULS spectra

of modal damping ratios, often based on simplifying assumptions. The achieved damping ratios cannot be calculated using the logarithmic decrement of free vibration as the modes are coupled due to non-classical damping. Veletsos and Ventura (1986) reviewed modal analysis of non-classically damped linear systems. Viscously damped systems that do not meet the classically damped conditions generally have complex-valued natural modes. Modal properties can be evaluated by complex eigenvalue analysis, summarized below.

The equation of motion for a system experiencing free vibration is given as Eq. 5, where $\mathbf{M}, \mathbf{K}$ and $\mathbf{C}$ are the mass, stiffness, and damping matrix of the system respectively. By defining the state space as Eq. 6, the state space representation of the system with $n$ modes of interest can be written as Eq. 7, where $\mathbf{I}$ is an $n \times n$ identity matrix, $\mathbf{0}$ is an $n \times n$ null matrix and $\mathbf{A}$ is the system matrix. The eigenvalues of $\mathbf{A}$ are complex conjugate pairs. For the $i$-th pair, the imaginary part of eigenvalue $s_{i}$ is the $i$-th damped circular frequency $\left(\omega_{d, i}\right)$ of the system. The damping ratio can be determined from the negative ratio of the real part $\operatorname{Re}\left(s_{i}\right)$ and modulus $\left|s_{i}\right|$ (Occhiuzzi 2009).

$$
\begin{gathered}
\mathbf{M} \ddot{\mathbf{x}}+\mathbf{C} \dot{\mathbf{x}}+\mathbf{K} \mathbf{x}=0 \\
\mathbf{z}=\left\{\begin{array}{c}
\mathbf{x} \\
\dot{\mathbf{x}}
\end{array}\right\} \\
\dot{\mathbf{z}}=\frac{d}{d t}\left\{\begin{array}{c}
\mathbf{x} \\
\dot{\mathbf{x}}
\end{array}\right\}=\left[\begin{array}{cc}
0 & \mathbf{I} \\
-\mathbf{M}^{-1} \mathbf{K} & -\mathbf{M}^{-1} \mathbf{C}
\end{array}\right]\left\{\begin{array}{l}
\mathbf{x} \\
\dot{\mathbf{x}}
\end{array}\right\}=\mathbf{A z}
\end{gathered}
$$

The mass, stiffness and damping matrices are required to conduct complex eigenvalue analysis. Although these matrices are not directly available in OpenSees, they can be calculated using the global system matrix $\left(\mathbf{K}^{*}\right)$ : a combination of $\mathbf{M}, \mathbf{K}$, and $\mathbf{C}$. The OpenSees command "printA" records the current global system matrix. The system matrix is equal to the stiffness matrix if static analysis is performed $(\mathbf{F}=\mathbf{K x})$. To determine $\mathbf{M}$ and $\mathbf{C}$, dynamic analyses were conducting using the Newmark integration method (Newmark coefficients of $\gamma=0.5$ and $\beta=0.25$ ). Equation 8 is the global system matrix with the Newmark integration method, where $\Delta t$ represents the time step used in the analysis (PEER). One analysis was conducted without Rayleigh damping and FVDs, allowing $\mathbf{M}$ to be determined. Rayleigh damping and FVDs were then added to the model. A second transient analysis was performed, allowing $\mathbf{C}$ to be determined.

$$
K_{t+\Delta \mathrm{t}}^{*}=K_{t}+\frac{\gamma}{\beta \Delta \mathrm{t}} C_{t}+\frac{1}{\beta \Delta \mathrm{t}^{2}} M
$$




\subsection{Comparison of target and achieved damping}

A comparison of the target and achieved damping ratio using the energy method achieved has not been previously performed. Each of the five benchmark building models was retrofitted with uniformly-distributed FVDs. The damper coefficients were calculated using the energy method formula (Eq. 4). The target damping ratio was increased by $5 \%$ for each iteration, giving a range of $10-45 \%$ total damping in the first mode. Table 5 compares the actual damping ratios calculated using the complex eigenvalue analysis described in Sect. 3.1 with the target ratios of the energy method. The energy formula was found to underestimate the achieved damping for all cases. The approximated damping ratio is closer to the target ratio for the shorter buildings as expected. This may be influenced by higher mode effects, which are more pronounced for the taller buildings.

\subsection{Modification of the energy formula}

The main advantage of the energy method formula is that calculations can be easily and quickly performed. However, it has been demonstrated that the approximation may only be accurate for low-rise structures. This section modifies the energy formula to decrease the variation between the target and achieved damping ratios, while maintaining the ease-ofuse advantage of a single formula.

The numerator of Eq. 4 is based on the energy dissipated by the dampers $\left(E_{D}\right)$ and the denominator is based on the maximum kinetic energy of the entire structure $\left(E_{k, o}\right)$. The equivalent viscous damping ratio in mode $n$ is given by Eq. 9. This equation was developed for a single degree-of-freedom system by Chopra (2012). The energy method formula was produced using Eq. 9, assuming this procedure can be extended to multi-degree-offreedom structures on a mode-by-mode basis with sufficient accuracy.

$$
\zeta_{d, n}=\frac{E_{D}}{4 \pi E_{k, o}}
$$

Considering harmonic motion defined as $u=u_{o} \sin \omega t$ for a single degree-of-freedom system, the viscous damper force $f_{D}=c \dot{u}=c u_{o} \cos \omega t$. The energy dissipated by viscous damping $\left(E_{D}\right)$ in one cycle of motion is given by Eq. 10. Expressing Eq. 10 in terms of the

Table 5 Damping ratios (\%) achieved using the original (Orig.) and modified (Mod.) energy formulas

\begin{tabular}{|c|c|c|c|c|c|c|c|c|c|c|}
\hline \multirow[t]{2}{*}{ Target } & \multicolumn{2}{|l|}{$4 \mathrm{~S}$} & \multicolumn{2}{|l|}{$8 \mathrm{~S}$} & \multicolumn{2}{|l|}{$16 \mathrm{~S}$} & \multicolumn{2}{|l|}{$4 \mathrm{D}$} & \multicolumn{2}{|l|}{$8 \mathrm{D}$} \\
\hline & Orig. & Mod. & Orig. & Mod. & Orig. & Mod. & Orig. & Mod. & Orig. & Mod \\
\hline 10 & 11 & 9 & 12 & 10 & 14 & 10 & 11 & 9 & 13 & 11 \\
\hline 15 & 17 & 15 & 19 & 16 & 23 & 16 & 17 & 15 & 21 & 17 \\
\hline 20 & 23 & 20 & 27 & 21 & 32 & 23 & 23 & 20 & 29 & 23 \\
\hline 25 & 29 & 25 & 33 & 27 & 41 & 29 & 29 & 24 & 36 & 29 \\
\hline 30 & 35 & 30 & 38 & 31 & 47 & 34 & 34 & 29 & 40 & 34 \\
\hline 35 & 40 & 34 & 42 & 36 & 49 & 40 & 39 & 34 & 43 & 38 \\
\hline 40 & 44 & 38 & 45 & 39 & 50 & 44 & 44 & 38 & 46 & 41 \\
\hline 45 & 48 & 42 & 48 & 42 & 51 & 48 & 48 & 41 & 48 & 43 \\
\hline
\end{tabular}


viscous damping ratio and natural frequency $\left(\omega_{n}\right)$, and given that the maximum strain energy is equal to the maximum energy, produces Eq. 11.

$$
\begin{gathered}
E_{D}=\int f_{D} d u=\pi c \omega u_{o}^{2} \\
\zeta=\frac{\omega_{n}}{\omega} \frac{E_{D}}{4 \pi E_{k, o}}
\end{gathered}
$$

The above analysis is true for a single degree-of-freedom system with a theoretical viscous damper. However, the formula is applied to other systems with energy dissipation to produce an equivalent viscous damping ratio. To define an equivalent viscous damping ratio for an actual structure, the energy dissipated in the structure during an experiment is equated to the viscous damping given by Eq. 11. It is assumed that the method can be applied on a mode-by-mode basis, and that the experiment producing the force-deformation relationship is conducted at $\omega=\omega_{n}$. Equation 11 then reduces to Eq. 9 used by the energy method.

The $\omega_{n} / \omega$ term should be considered, as the response of a structure to earthquake ground motions cannot be assumed to occur at $\omega=\omega_{n}$. It was opted to use the inverse of the modal mass participation factor as a proxy for the frequency ratio term. This value serves as an approximation for the contribution of each modal response to the total response of the system during an arbitrary motion. The calculation of the modal mass participation factor of mode $n\left(M_{n}^{p}\right)$, shown in Eq. 12, does not significantly increase the effort involved in the energy method. Determining this factor only requires the mode shape, the mass matrix and the influence vector $\left(i_{v}\right)$. The mode shape and mass matrix are already required for the energy formula, while determining the influence vector is a straightforward process. The modified energy formula is presented in Eq. 13, with all terms previously defined. This equation is limited to the case of linear FVDs.

$$
\begin{gathered}
M_{n}^{p}=\frac{\left(\phi^{T} M i_{v}\right)^{2}}{\phi^{T} M \phi} \frac{1}{M_{\text {total }}} \\
\zeta_{d, n}=\frac{T_{n} \sum_{j} C_{j} \cos ^{2} \theta_{j} \phi_{r j}^{2}}{4 \pi M_{n}^{p} \sum_{i} m_{i} \phi_{i}^{2}}
\end{gathered}
$$

The modified formula was used to calculate the damper coefficients for all building designs and all levels of damping previously considered in this paper. Complex eigenvalue analysis was then used to determine the achieved damping ratios. The achieved damping ratios are shown in Table 5. The achieved damping ratios are relatively close to the target damping ratio in comparison to the original energy method results.

The mean absolute relative error (MARE) was determined using Eq. 14 to compare the accuracy of the original and modified energy formulas, where $\zeta_{T, d}$ and $\zeta_{A, d}$ are the target and achieved damping ratio for each level of damping $d$ considered, respectively, and $n_{d}$ is the number of damping levels considered. The MARE results considering all levels of damping and all buildings expressed as a percentage are shown in Table 6.

$$
\text { MARE }=\frac{1}{n_{d}} \sum_{d}\left(\frac{\zeta_{T, d}-\zeta_{A, d}}{\zeta_{T, d}}\right)
$$


Table 6 Mean absolute relative error of the energy formulas

\begin{tabular}{lccccc}
\hline Formula & \multicolumn{5}{l}{ Mean absolute relative error } \\
\cline { 2 - 6 } & $4 \mathrm{~S}(\%)$ & $8 \mathrm{~S}(\%)$ & $16 \mathrm{~S}(\%)$ & $4 \mathrm{D}(\%)$ & $8 \mathrm{D}(\%)$ \\
\hline Original & 13 & 23 & 44 & 11 & 29 \\
Modified & 3 & 4 & 11 & 4 & 10 \\
\hline
\end{tabular}

The modified formula results in a lower error for all buildings with respect to the original energy formula. A substantial improvement is realized for the eight- and 16-storey structures. This suggests that the modified energy formula is an improvement on the original formula for uniformly-distributed dampers and should be considered in future studies.

\section{Optimal amount of damping}

The amount of damping in a building significantly influences structural response during an earthquake. Occhiuzzi (2009) examined many damped buildings detailed in previous literature and found a maximum of $20-25 \%$ total damping in the first mode to be ideal. Additional damping past this level increased accelerations, while the further reductions in interstorey drift were deemed negligible. However, solely the author's judgement was used to determine that the interstorey drift reductions were negligible. Further investigation on this topic is needed. Christopoulos and Filiatrault (2006) stated that a maximum total damping of $35 \%$ in the first mode can reasonably be achieved with FVDs. An investigation was conducted to determine the optimal amount of damping with respect to repair costs.

Damping is included in each of the five structures using Rayleigh damping and FVDs using a uniform distribution. Repair costs are determined for a range of 5-45\% total damping in the first mode, with the ratio increasing by 5\% for each iteration. Damper coefficients were calculated to achieve each target level of damping considering complex eigenvalue analysis. It is recognized that the addition of FVDs into a structure can significantly increase column axial forces (Uriz and Whittaker 2001; Martinez-Rodrigo and Romero 2003). If the maximum axial load in a column is increased, it must be accounted for in the retrofit design. The columns of the retrofitted structures will be examined against failure using the design provisions of Eurocode 3 (CEN 2010a, b, c).

\subsection{Engineering demand parameter (EDP) results}

Time history analyses were conducted using the retrofitted building models and the ULS and SLS ground motion suites. The peak EDP values from each time history analyses were determined. The mean of the peak absolute floor accelerations and interstorey drifts are shown in Fig. 4 for the eight-storey standard and drift buildings for illustration.

Both drifts and accelerations are significantly reduced by the introduction of supplemental damping. It can be observed that interstorey drifts are more sensitive than accelerations to the level of damping. The peak interstorey drift ratios (IDRs) continue to decrease as the damping increases. The peak accelerations of all buildings retrofitted with FVDs are similar, irrespective of the amount of supplemental damping. Occhiuzzi (2009) found that as total damping increased beyond the range of 20-25\%, accelerations increased and negligible further reduction in IDR was achieved. However, the method used to 

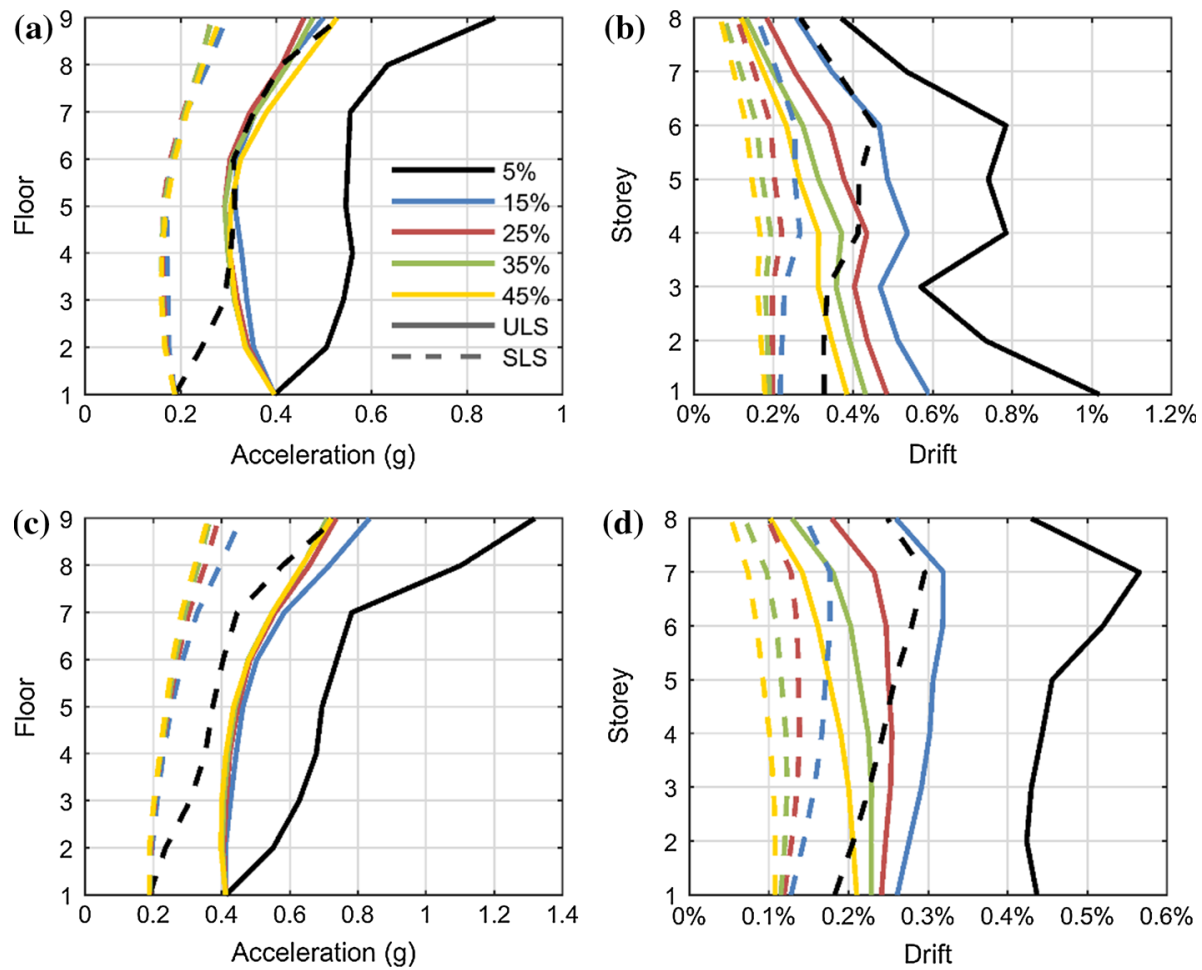

Fig. 4 Comparison of the mean peak EDPs considering several levels of damping. a $8 \mathrm{~S}$ acceleration, b $8 \mathrm{~S}$ drift, c 8D acceleration, d 8D drift

classify the IDR reductions as negligible is unclear. Within the investigated range of $5-45 \%$ total damping, drifts decrease with increased damping. Due to the complexity of the relationship between structural parameters and damping, the expected earthquake damage should be examined to quantify the effects of increased damping in meaningful terms.

\subsection{Damping ratio-repair cost relationship}

Seismic performance assessments using the FEMA P-58 procedure (FEMA 2012a, b) were conducted for the FVD-retrofitted buildings. Direct repair costs in 2011 US dollars resulting from damage to building assets are calculated, while indirect costs due to building downtime are out of scope.

The damping ratio-repair cost relationship is represented using the mean and 90th percentile repair costs. The repair costs for each level of total damping are normalized by the repair costs of the buildings without supplemental damping (i.e. 5\% inherent damping). The damping ratio-repair cost relationship is shown in Fig. 5 using FVDs with coefficients from the generalized modal method. The optimal level of damping for each building and limit state is indicated in the figure. Optimal damping is defined as the lowest level of damping that produces a cost within $2.5 \%$ of the minimum repair cost. The margin of $2.5 \%$ is selected to reflect the uncertainty in the assessment procedure. It is generally assumed 
(a)

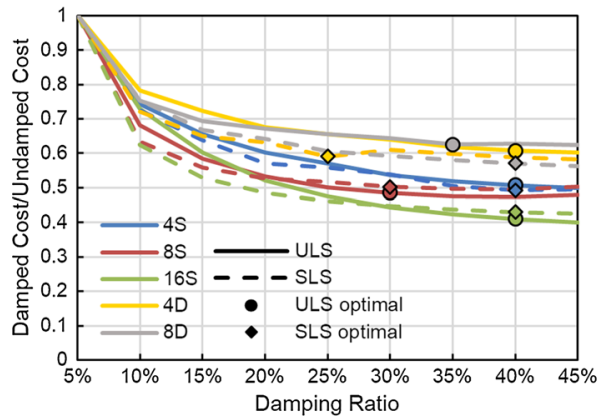

(b)

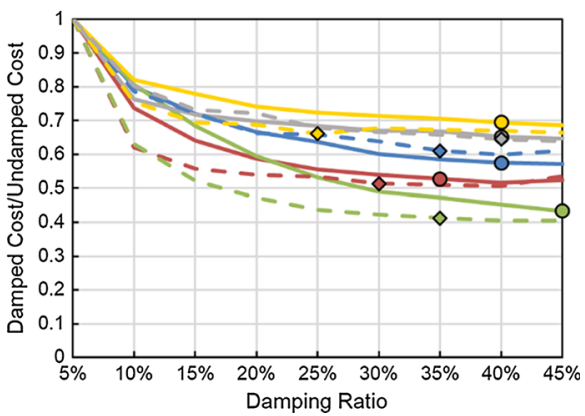

Fig. 5 Total damping ratio-repair cost relationship, with optimal damping values indicated. a Mean costs, b 90 th percentile costs

that there is a positive relationship between the amount of damping and damper costs. As a result, the lowest level of damping producing the near-minimum cost is the most desirable.

Several trends regarding the damping ratio-repair cost relationship can be identified:

1. Repair costs decrease as the total damping is increased. Diminishing returns are observed.

2. The reduction in repair cost due to damping increases as the flexibility of the building is increased. For example, the damped ULS repair cost of building $16 \mathrm{~S}$ reduces to $40 \%$ of the undamped cost, while the damped cost of building 4D plateaus at $60 \%$ of the undamped cost.

3. The SLS costs experience greater reductions at lower levels of damping than the ULS costs.

The optimal damping level is between 25 and $40 \%$ damping for the mean results, and between 25 and $45 \%$ for the 90th percentile results. This is in contrast to a previously suggested optimal damping of 20-25\% total damping based on EDPs (Occhiuzzi 2009). This highlights that retrofit methods may be enhanced by using repair costs, rather than structural parameters, when making decisions. However, it should be noted that the optimal amount of damping will be dependent on the building properties such as period of vibration and strength. The results presented in this section can serve as valuable guidance for selecting an initial damping target.

\section{FVD vs drift performance}

Designing buildings to reach the advanced drift criteria and using FVDs are two methods with the same aim: to improve the seismic performance of standard buildings. The resulting performance of both methods is compared. The drift designs are used as the benchmarks for the four- and eight-storey retrofitted structures, while $16 \mathrm{~S}$ is used as a benchmark for the 16-storey retrofitted structure. 


\subsection{Required damping}

The standard buildings were designed to reach a SLS drift limit of $0.5 \%$ and a ULS drift limit of $1.0 \%$. The drift design buildings were created by targeting a reduced ULS drift of $0.5 \%$. In order to retrofit the standard buildings to reach the drift design performance level, the amount of supplemental damping required to attain the ULS drift target was determined. The damping correction factor required to realize the performance improvement was calculated using Eq. 1 and found to be $0.5(0.5 \% / 1 \%)$. The level of supplemental damping corresponding to $\eta=0.5$ was determined to be $35 \%$ using the Eurocode method and 37\% using the ASCE method. Although both methods produce comparable levels of damping, the Eurocode 8 method is only valid for $\eta \geq 0.55$. As a result, a target overall damping ratio of $37 \%$ was selected. This target is within the identified optimal range of damping considering repair costs.

To size and place the dampers, the desired supplemental damping $(37-5 \%=32 \%)$ was converted to viscous damping coefficients assuming uniform damper placement. The energy method from Whittaker et al. (2003), the modified energy formula developed in this paper, and complex eigenvalue analysis were used to calculate the $C_{i}$ values. Table 7 presents the resulting damper coefficients and the relative error (RE) with respect to the general modal analysis. The RE is calculated using Eq. 15 , where $C_{i, \text { actual }}$ and $C_{i, \text { estimate }}$ are the actual and estimated damper coefficients, respectively.

$$
\mathrm{RE}=\frac{C_{i, \text { actual }}-C_{i, \text { estimate }}}{C_{i, \text { actual }}} \times 100 \%
$$

The energy method results in significant error for the eight- and 16-storey structures. The modified energy method produces coefficients with a reduced error in comparison to the original energy method. In the following discussion, the modified energy method is used to determine the damper coefficients unless noted.

\subsection{Time history analyses}

\subsubsection{EDPs}

EDPs of the standard designs retrofitted with FVDs were recorded during each time history analyses. These EDPs and the EDPs from the drift designs are compared in Fig. 6 for the four- and eight-storey structures, where $R$ refers to the FVD-retrofitted standard designs and $D$ refers to the drift designs. The means of the peak values are displayed for both limit states. The peak floor velocity values do not significantly vary between the FVD and drift designs, and are omitted due to space constraints. Although the dampers influence relative velocities, the relative values are insignificant compared to the ground velocity and the impact on absolute velocities is modest.

Table 7 Damping coefficient required to produce $32 \%$ supplemental damping and the resulting error

\begin{tabular}{lrrrlllll}
\hline Method & \multicolumn{3}{l}{$C_{i}(\mathrm{kN} \mathrm{s} / \mathrm{mm})$} & & \multicolumn{3}{l}{ Relative error } \\
\cline { 2 - 3 } \cline { 7 - 8 } & $4 \mathrm{~S}$ & $8 \mathrm{~S}$ & $16 \mathrm{~S}$ & & $4 \mathrm{~S}$ & $8 \mathrm{~S}$ & $16 \mathrm{~S}$ \\
\hline Energy & 10.0 & 19.4 & 23.6 & $-18 \%$ & $-35 \%$ & $-80 \%$ \\
Modified Energy & 8.1 & 14.6 & 15.4 & $5 \%$ & $-1 \%$ & $-18 \%$ \\
General Modal & 8.5 & 14.4 & 13.1 & & $\mathrm{n} / \mathrm{a}$ & $\mathrm{n} / \mathrm{a}$ & $\mathrm{n} / \mathrm{a}$ \\
\hline
\end{tabular}


(a)

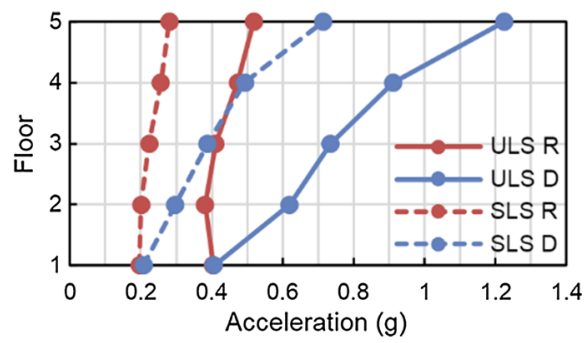

(c)

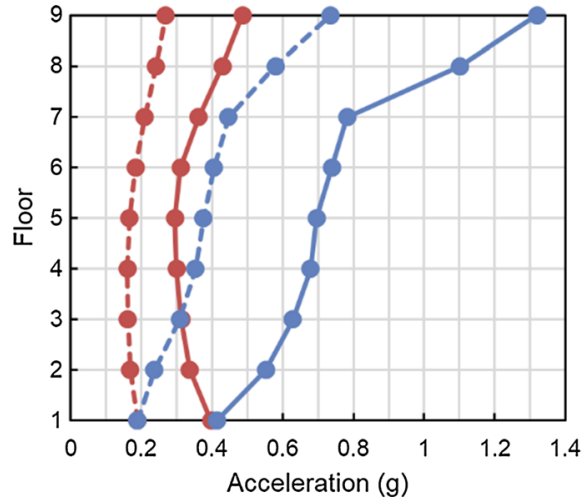

(b)

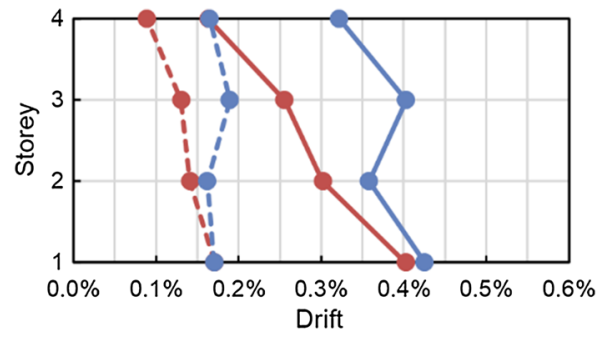

(d)

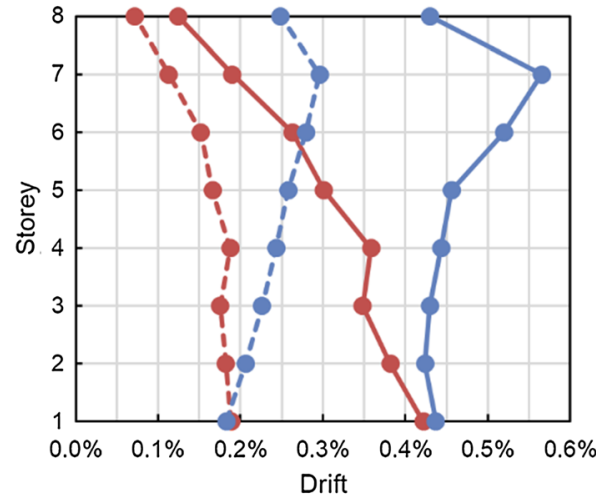

Fig. 6 Comparison of mean peak structural response parameters of the standard buildings with FVDs and the drift designs. a Four-storey absolute floor accelerations, b four-storey interstorey drifts, c eight-storey absolute floor accelerations, $\mathbf{d}$ eight-storey interstorey drifts

Accelerations at the first floor remain unchanged between the two building sets as expected. This parameter is governed by the ground acceleration and is unaffected in these analyses that do not take ground-structure interaction into account. Another retrofit strategy must be incorporated to improve acceleration-sensitive performance at the ground level, such as equipment isolation. Accelerations at all floors above the ground level exhibit significant reductions for the FVD-retrofitted buildings due to the increased total damping. The interstorey drifts of the FVD-retrofitted buildings also showed significant improvements with respect to the drift designs, excluding the first storey. The target ULS drift limit of $0.5 \%$ is achieved for both FVD structures as expected.

The peak EDPs for the 16-storey structure retrofitted with dampers and the EDPs from the standard design are compared in Fig. 7, where $R$ refers to the FVD-retrofitted building and $S$ refers to the standard building. The peak absolute floor accelerations are significantly improved by the FVD retrofit, excluding the ground floor. The target ULS drift limit of $0.5 \%$ has been reached using FVDs. This IDR limit was unable to be met using the drift design approach. The drift concentration at storey 13 in the standard building (due to higher mode effects) is also prevented in the damped structure. The Del Gobbo et al. (2018) study noted that the standard building may experience a soft-storey at this level. However, the peak absolute floor velocities showed little to no reductions. 
(a)

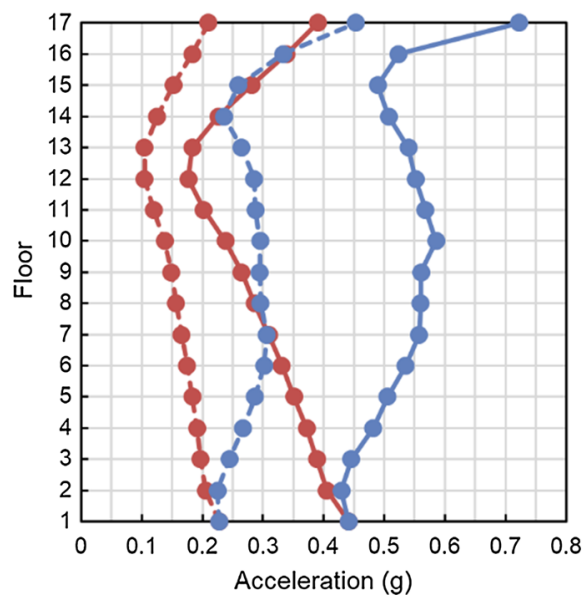

(b)

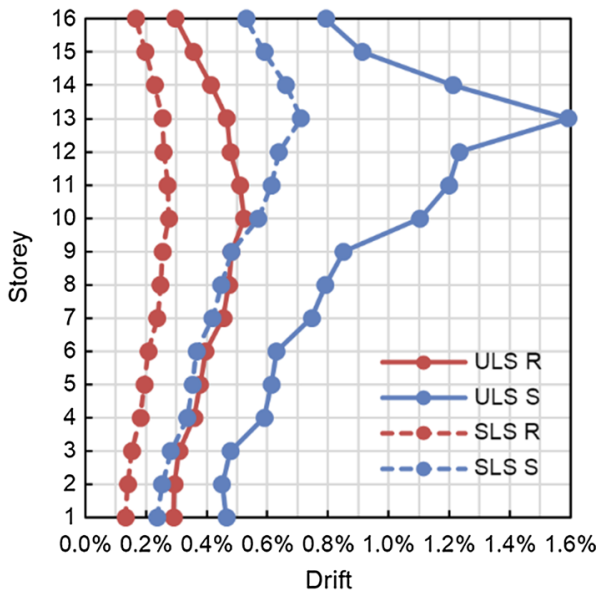

Fig. 7 Comparison of mean peak structural response parameters of $16 \mathrm{~S}$ with and without FVDs. a Absolute floor accelerations, $\mathbf{b}$ interstorey drifts

\subsubsection{Nonlinear structural response}

The nonlinear brace response of interest can be classified as buckling or yielding. Brace yielding and buckling was determined by examining the force-elongation relationship for each member during each ground motion analysis. Nonlinear brace behavior did not occur in the FVD-retrofitted buildings during the SLS. The mean percentage of braces in the damped structures that buckle or yield considering all ULS earthquakes are shown in Table 8. Minor nonlinear brace behavior is observed. In comparison, a considerable number of braces (mean of 56-79\%) were shown to buckle during the ULS for the standard buildings (Del Gobbo et al. 2018). The use of FVDs would prevent the need for extensive structural repairs.

The addition of FVDs into a structure can significantly increase column axial forces (Uriz and Whittaker 2001; Martinez-Rodrigo and Romero 2003). If the maximum axial load in a column is increased, it must be accounted for in the retrofit design. The columns of the retrofitted structures were examined at each timestep of the time history analyses against failure using the design provisions of Eurocode 3 (CEN 2010a, b, c). Column capacity failure did not occur, whereas column buckling capacity in axial loading-bending was exceeded in a small number of ULS analyses for the standard buildings (Del Gobbo et al. 2018).

Table 8 Mean percentage of braces that buckle or yield considering all ULS analyses

\begin{tabular}{lllr}
\hline Condition & $4 \mathrm{R}(\%)$ & $8 \mathrm{R}(\%)$ & $16 \mathrm{R}(\%)$ \\
\hline Yield & 3 & 2 & 0 \\
Buckle & 6 & 6 & 13 \\
\hline
\end{tabular}




\subsubsection{Damper costs}

The required damper investment should be considered when evaluating FVD retrofit options. Gidaris and Taflanidis (2015) derived a cost equation for commercially available dampers. The equation is reproduced in Eq. 16, where Cost $_{j}$ is the cost in dollars of damper $j$ and $F_{\text {max }, j}$ is the maximum force capacity of damper $j$ in $\mathrm{kN}$. Total damper investment based on the maximum ULS forces over all time history analyses are shown in Table 9. The increase in structural cost due to the drift designs with respect to the standard designs from Del Gobbo et al. (2018) are also reproduced for comparison.

$$
\operatorname{Cos} t_{j}=96.88\left(F_{\max , j}\right)^{0.607}
$$

The FVD retrofits produce total building costs that are comparable to the use of drift designs. The total damper investment is less than $3 \%$ of the standard building cost. The increase in building value will be considered during the FEMA P-58 analyses of the FVDretrofitted structures. It is recognized that the damper cost formula is an approximation, and does not capture additional costs such as frame strengthening or lost rentable space.

\subsection{FEMA P-58 results}

\subsubsection{FVD retrofit and drift design}

The seismic performance of the four- and eight-storey FVD-retrofitted buildings can be evaluated with respect to the drift designs. Total repair costs, costs considering the contributing EDPs, and costs considering fragility groups are investigated.

5.3.1.1 Total repair costs Cumulative distribution functions of the ULS and SLS total repair costs normalized by the respective building cost are shown in Fig. 8 for the four- and eight-storey buildings. The standard $(S)$, drift $(D)$, and FVD-retrofitted $(R)$ structures are shown. The non-normalized cumulative distribution functions are shown in Fig. 9 for the $R$ and $D$ sets.

The ULS repair costs of the FVD-retrofitted buildings are approximately equal to the SLS costs of the drift designs. The median ULS repair costs of the drift designs exceed $40 \%$ of the building values. Owners often elect to demolish and replace the existing building if repair costs exceed this limit (FEMA 2012a, b). In comparison, the 90th percentile ULS repair costs of the retrofitted buildings are below the P-58 demolish limit. This represents a significant performance improvement for the buildings with FVDs over the drift designs, as the need to demolish and replace the retrofitted buildings following a ULS earthquake is prevented in all but the most extreme cases.

Table 9 Comparison of the increases in building cost due to the FVD retrofit and the drift design

\begin{tabular}{lll}
\hline Building & FVD retrofit & Drift design \\
\hline Four-storey & $2.8 \%(\$ 106,000)$ & $1.8 \%(\$ 70,000)$ \\
Eight-storey & $2.9 \%(\$ 250,000)$ & $5.1 \%(\$ 440,000)$ \\
16 -storey & $2.9 \%(\$ 530,000)$ & $\mathrm{n} / \mathrm{a}$ \\
\hline
\end{tabular}




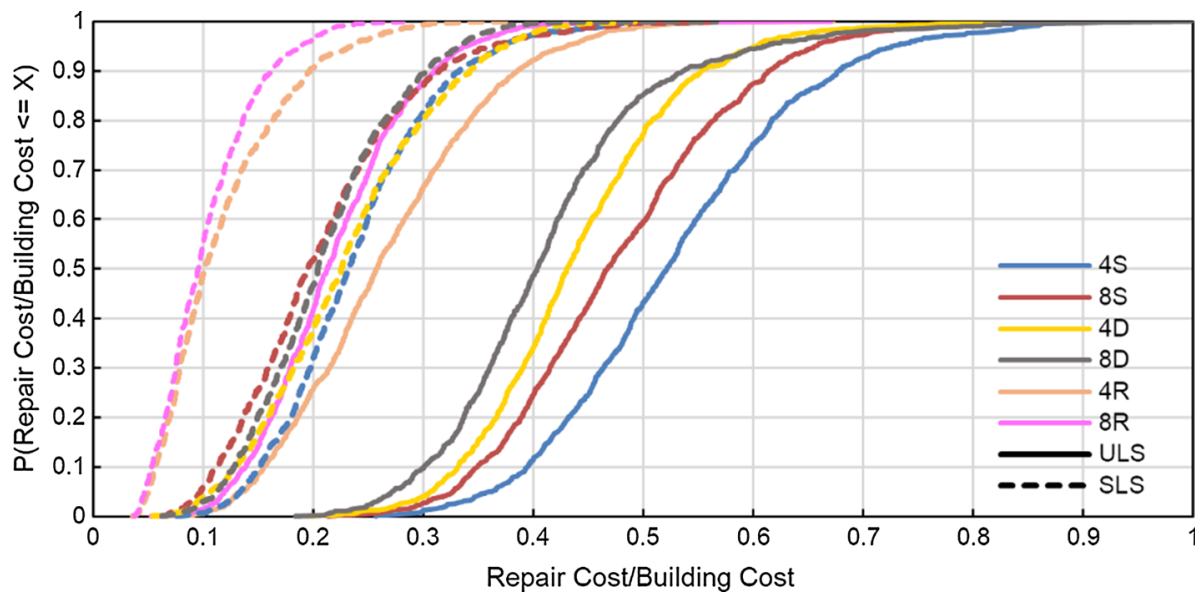

Fig. 8 Cumulative distribution functions of total repair costs normalized by building value for the four- and eight-storey designs
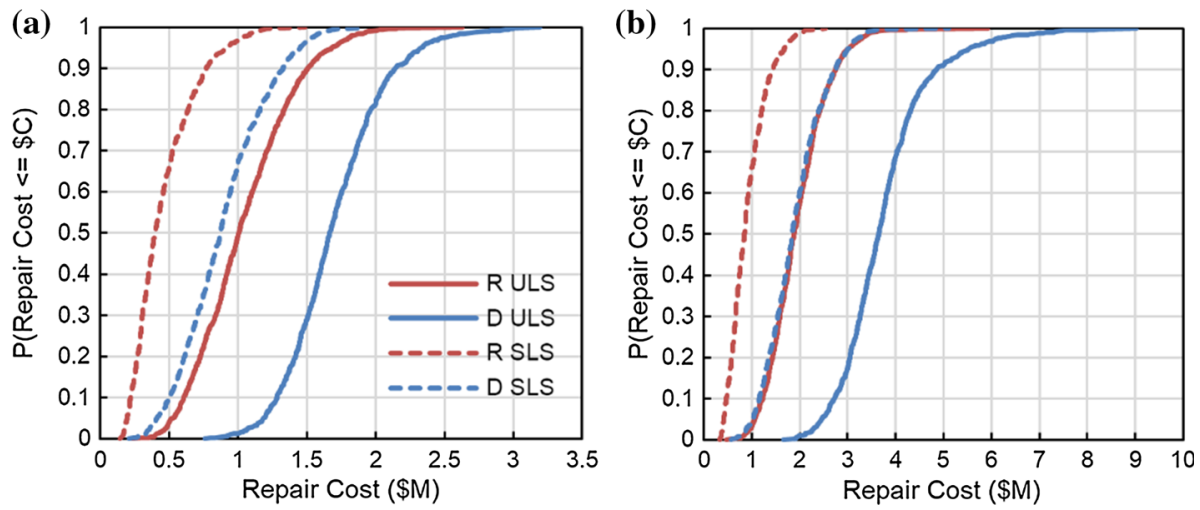

Fig. 9 Comparison of the repair cost cumulative distributions for the FVD-retrofitted standard buildings and drift designs. a Four-storey, b eight-storey

The median SLS repair costs for the retrofitted buildings are under $10 \%$ of the building values. In comparison, the SLS median values for the drift designs were over $20 \%$. A total loss of under $10 \%$ is closer towards achieving a level of damage that will minimize effects on building serviceability.

5.3.1.2 Repair costs and EDPs Repair costs from the seismic performance assessment can be attributed to the EDP that generated the damage. This is shown in Fig. 10 for the FVD-retrofitted and drift design buildings. The results of the original method are excluded, as the disaggregation was nearly identical to the modified method.

The FVD buildings significantly reduce both drift and acceleration damage when compared with the drift designs. The reduction in acceleration damage is greater than the reduction in drift damage. This can be rationalized by the drift design approach, which minimizes interstorey drifts at the expense of increased accelerations. Minimal drift damage is produced in the SLS for both building sets. Acceleration-sensitive damage 

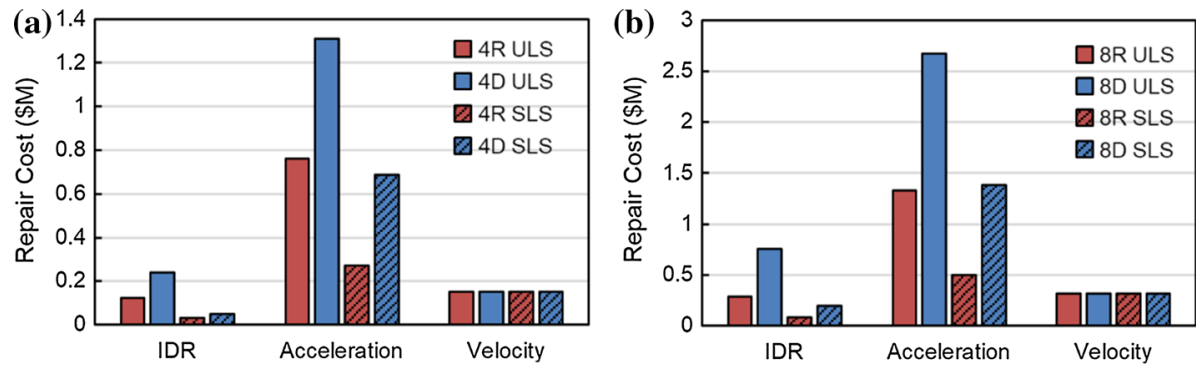

Fig. 10 Mean repair costs grouped by EDP for the FVD-retrofitted and drift designs. a Four-storey buildings, $\mathbf{b}$ eight-storey buildings

accounts for the majority of damage in all cases, emphasizing the importance of acceleration on seismic performance. Velocity damage is unchanged, confirming that FVDs cannot meaningfully improve velocity-sensitive seismic performance. Another technique such as anchorage may be used to prevent component toppling due to high absolute floor velocities.

Large acceleration repair costs are generated on floor one of the FVD buildings due to a concentration of acceleration-sensitive nonstructural components such as HVAC equipment. Repair costs could be further decreased if acceleration-sensitive nonstructural systems were relocated from the ground floor to any upper floor with reduced accelerations.
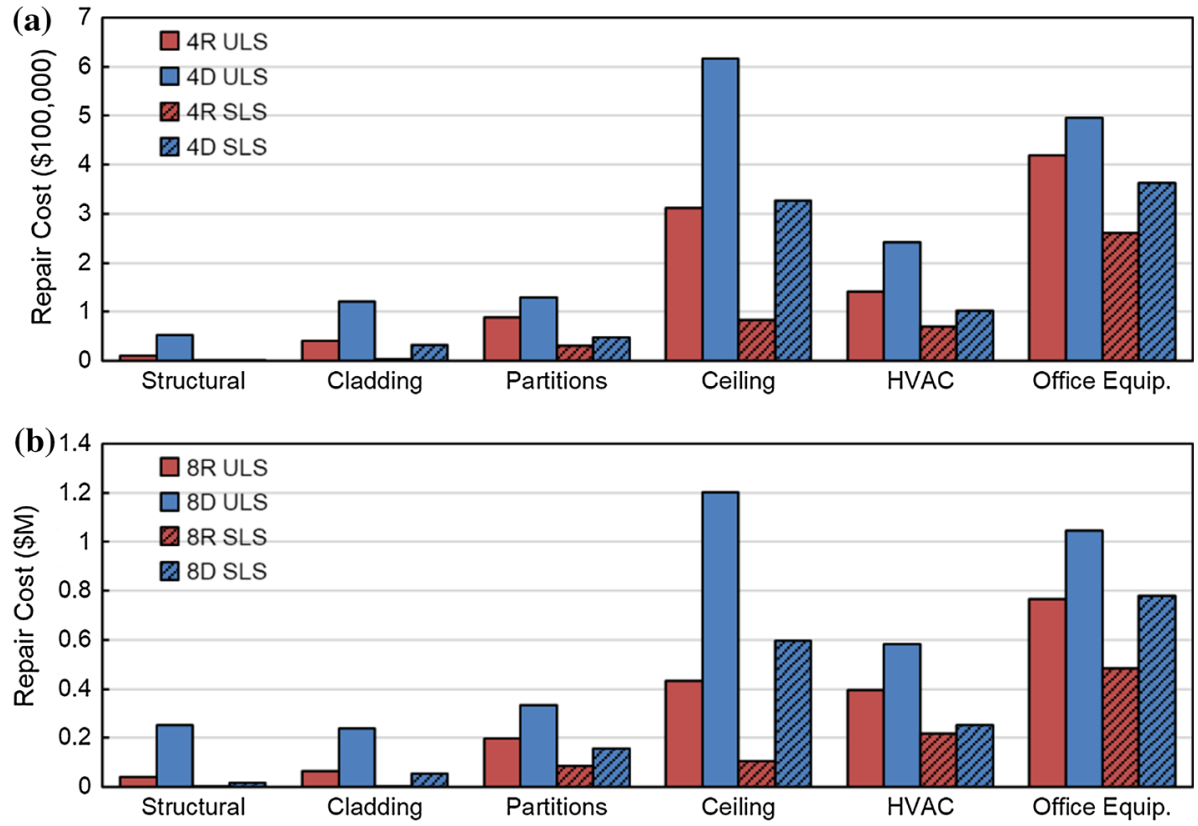

Fig. 11 Comparison of fragility-sorted repair costs for the FVD-retrofitted standard structures and the drift design structures. a Four-storey buildings, b eight-storey buildings 
5.3.1.3 Repair costs and fragility groups The mean repair costs for each structural and nonstructural fragility group of the four- and eight-storey buildings were determined. The fragility-sorted repair costs are shown in Fig. 11. The fragility groups with negligible repair costs are excluded.

Structural damage is negligible in the FVD-retrofitted buildings. This concurs with the investigation on nonlinear structural behavior and gives confidence to the P-58 results. In comparison, the four- and eight-storey drift buildings experience ULS structural damage. Structural damage would introduce significant delays to re-occupancy following an earthquake. This identifies a significant improvement in seismic performance for the FVDretrofitted buildings. Preventing structural damage is a major step towards achieving building serviceability following a ULS level earthquake.

Significant repair costs can be attributed to nonstructural systems. This emphasizes the importance of considering nonstructural seismic performance when designing for a rapid return to building occupancy. Attaining a target level of seismic performance requires the harmonization of structural and nonstructural performance.

\subsubsection{6-storey FVD retrofit}

The FVD-retrofitted four- and eight-storey standard structures have been shown to outperform the comparable drift design structures. Although the 16-storey structure was unable to be designed to meet the advanced drift requirements using the drift design approach, the desired drift performance was obtained using FVDs.

The expected total repair costs for the damped and undamped 16-storey structures are represented by cumulative distribution functions in Fig. 12. Both the ULS and the SLS repair cost distributions are provided.

The ULS repair costs of the building with FVDs are less than or equal to the SLS costs of the standard design. It is probable that building $16 \mathrm{~S}$ would be demolished and replaced following a ULS earthquake, as the median costs are approximately $50 \%$ of the building value (FEMA 2012a, b). In comparison, structure 16R reaches the damage limit corresponding to building replacement ( $40 \%$ of building value) at the 98 th percentile. This represents a significant performance improvement for the buildings with FVDs, as the need to demolish and replace the retrofitted buildings following a ULS earthquake is prevented. The median SLS repair costs for 16R is $9 \%$ of the building value, under half of the standard building damage of $20 \%$.

Fig. 12 Cumulative distribution functions of repair costs for the 16-storey buildings

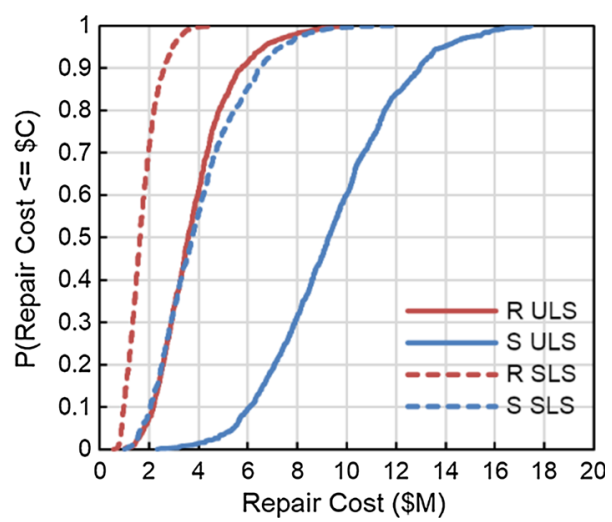




\section{Conclusions}

This paper has demonstrated a method of optimizing seismic performance of buildings through the addition of viscous dampers, by minimizing the total cost of both structural and nonstructural damage.

It was found that the energy formula underestimated the damping achieved by uniformly distributed viscous dampers. The energy method formula was modified to improve the accuracy of the damping ratio calculations by incorporating the effective modal mass. The mean absolute relative error between the target and achieved damping ratios was improved in comparison to the original energy method. The modified energy formula can be used to rapidly select the linear damper coefficients for a desired level of total damping and should be considered in future studies.

The optimal damping to minimize earthquake repair costs was found to be between 25 and $45 \%$ (considering uniform damping and linear FVDs). This contrasts with a previously suggested optimal damping of 20-25\% total damping based on EDPs (Occhiuzzi 2009). The damping-repair cost relationship can provide insight when selecting levels of damping for structural design and retrofit. While practical considerations may sometimes prevent implementation of the highest levels of damping considered here, this highlights that retrofit decisions may be improved by using repair costs, rather than structural parameters.

The standard designs were retrofitted with FVDs to reach the IDR limit of a set of comparator buildings designed to very strict drift limits. Excluding the ground level, peak floor accelerations and interstorey drifts of the FVD-retrofitted buildings were significantly improved with respect to the drift designs. Examining the expected repair costs revealed that the FVD-retrofitted buildings significantly outperform the drift designs for both the ULS and the SLS. Although the ULS repair costs of the drift designs decrease with respect to the standard buildings, the median repairs are still above the demolish limit (40\% of the building value). In comparison, the 90th percentile ULS repair costs of the FVD-retrofitted buildings are below this limit. This represents a significant advantage of using FVDs to retrofit buildings over the drift designs, as the probability of demolition following a ULS earthquake is reduced. The median SLS repair costs for the FVD buildings are approximately half of the drift design costs.

Open Access This article is distributed under the terms of the Creative Commons Attribution 4.0 International License (http://creativecommons.org/licenses/by/4.0/), which permits unrestricted use, distribution, and reproduction in any medium, provided you give appropriate credit to the original author(s) and the source, provide a link to the Creative Commons license, and indicate if changes were made.

Funding This work was supported by the University of Oxford [Clarendon Fund], and the Natural Sciences and Engineering Research Council of Canada [CGS M, PSG D].

\section{References}

American Society of Civil Engineers (ASCE) (2013) Minimum design loads for building and other structures, ASCE/SEI 7-10

Astrella MJ, Whittaker AS (2005) The performance-based design paradigm. Technical report MCEER-050011. University at Buffalo, State University of New York, Buffalo

CEN (2010a) Eurocode: basis of structural design. British Standards Institute, European Committee for Standardization (CEN), Brussels, Belgium

CEN (2010b) Eurocode 1: actions on structures. British Standards Institute, European Committee for Standardization (CEN), Brussels, Belgium 
CEN (2010c) Eurocode 3: design of steel structures. British Standards Institute, European Committee for Standardization (CEN), Brussels, Belgium

CEN (2013) Eurocode 8: design of structures for earthquake resistance-part 1: general rules, seismic actions and rules for buildings

Charney FA (2008) Unintended consequences of modeling damping in structures. J Struct Eng 134:581-592

Chen C, Mahin SA (2012) Performance-based seismic demand assessment of concentrically braced steel frame buildings. PEER Report 2012/103, Pacific Earthquake Engineering Research Center, University of California, Berkeley

Chopra AK (2012) Dynamics of structures, 4th edn. Prentice Hall, New Jersey

Christopoulos C, Filiatrault A (2006) Principles of passive supplemental damping and seismic isolation. IUSS Press, Pavia

D’Aniello M, La Manna Ambrosino G, Portioli F, Landolfo R (2013) Modelling aspects of the seismic response of steel concentric braced frames. Steel Compos Struct 15:539-566

Dall'Asta A, Tubaldi E, Ragni L (2016) Influence of the nonlinear behavior of viscous dampers on the seismic demand hazard of building frames. Earthq Eng Struct Dyn 45:149-169

Del Gobbo GM, Williams MS, Blakeborough A (2017) Seismic performance assessment of a conventional multi-storey building. Int J Disaster Risk Sci 8:237-245

Del Gobbo GM, Williams MS, Blakeborough A (2018) Seismic performance assessment of eurocode 8-compliant concentric braced frame buildings using FEMA P-58. Eng Struct 155:192-208

Dicleli M, Mehta A (2007) Seismic performance of chevron braced steel frames with and without viscous fluid dampers as a function of ground motion and damper characteristics. J Constr Steel Res 63:1102-1115

FEMA (2012a) FEMA P-58, seismic performance assessment of buildings, volume 2-implementation guide. Department of Homeland Security, Washington, DC

FEMA (2012b) FEMA P-58, seismic performance assessment of buildings, methodology and implementation. Department of Homeland Security, Washington, DC

Gidaris I, Taflanidis AA (2015) Performance assessment and optimization of fluid viscous dampers through life-cycle cost criteria and comparison to alternative design approaches. Bull Earthq Eng 13:1003-1028

Hwang J-S, Lin W-C, Wu N-J (2013) Comparison of distribution methods for viscous damping coefficients to buildings. Struct Infrastruct Eng 9:28-41

Jarrett JA, Judd JP, Charney FA (2015) Comparative evaluation of innovative and traditional seismicresisting systems using the FEMA P-58 procedure. J Constr Steel Res 105:107-118

Karamanci E, Lignos D (2014) Computational approach for collapse assessment of concentrically braced frames in seismic regions. J Struct Eng 140:A4014019

Kostic SM, Filippou FC (2012) Section discretization of fiber beam-column elements for cyclic inelastic response. J Struct Eng 138:592-601

Landi L, Conti F, Diotallevi PP (2015) Effectiveness of different distributions of viscous damping coefficients for the seismic retrofit of regular and irregular RC frames. Eng Struct 100:79-93

Lopez Garcia D, Soong TT (2002) Efficiency of a simple approach to damper allocation in MDOF structures. J Struct Control 9:19-30

Martinez-Rodrigo M, Romero ML (2003) An optimum retrofit strategy for moment resisting frames with nonlinear viscous dampers for seismic applications. Eng Struct 25:913-925

Mayes RL, Wassim IN (2005) Comparative seismic performance of four structural systems and assessment of recent AISC BRB test requirements. In: SEAOC 74th Annual Convention. pp 251-264

Mayes R, Wetzel N, Weaver B, Tam K, Parker W, Brown A, Pietra D (2013) Performance based design of buildings to assess and minimize damage and downtime. Bull NZ Earthq Eng 46(1):40-55

McKenna F (2017) OpenSees. Version 2.4.6. Open system for earthquake engineering simulation. PEER

Occhiuzzi A (2009) Additional viscous dampers for civil structures: analysis of design methods based on effective evaluation of modal damping ratios. Eng Struct 31:1093-1101

Palermo M, Muscio S, Silvestri S et al (2013) On the dimensioning of viscous dampers for the mitigation of the earthquake-induced effects in moment-resisting frame structures. Bull Earthq Eng 11:2429-2446

Pavlou E, Constantinou MC (2006) Response of nonstructural components in structures with damping systems. J Struct Eng 132:1108-1117

PEER (2013) PEER NGA-WEST 2 ground motion database. http://ngawest2.berkeley.edu/site

PEER OpenSees command manual. http://opensees.berkeley.edu/wiki/index.php/Command_Manual. Accessed 1 Jun 2017

Porter KA, Kiremidjian AS (2001) Assembly-based vulnerability of buildings and its uses in seismic performance evaluation and risk-management decision-making. The John A. Blume Earthquake Engineering Center, Stanford 
Solomos G, Pinto A, Dimova S (2008) A review of the seismic hazard zonation in national building codes in the context of Eurocode 8. JRC Sci Tech Reports

Tata Steel Europe Limited (2014) Tata Steel sections interative 'blue book', Version 5.4. The Steel Construction Institute, Berkshire, UK

Terzic V, Mahin SA, Comerio M (2014) Comparative life-cycle cost and performance analysis of structural systems for buildings. In: 10th national conference on earthquake engineering frontiers of earthquake engineering NCEE 2014

Tsitos A, Bravo-Haro MA, Elghazouli AY (2018) Influence of deterioration modelling on the seismic response of steel moment frames designed to Eurocode 8. Earthq Eng Struct Dyn 47:356-376

Uriz P, Mahin S (2008) Toward earthquake-resistant design of concentrically braced steel-frame structures. PEER report 2008/08. University of California, Berkeley. Berkeley, USA

Uriz P, Whittaker AS (2001) Retrofit of pre-northridge steel moment-resisting frames using fluid viscous dampers. Struct Des Tall Build 10:371-390

Uriz P, Filippou FC, Mahin SA (2008) Model for cyclic inelastic buckling of steel braces. J Struct Eng 134:619-628

Vargas RE, Bruneau M (2006) Analytical investigation of the structural fuse concept. Technical report MCEER- 06-0004. University at Buffalo, State University of New York, Buffalo

Vargas R, Bruneau M (2007) Effect of supplemental viscous damping on the seismic response of structural systems with metallic dampers. J Struct Eng 133:1434-1444

Veletsos AS, Ventura CE (1986) Modal analysis of non-classically damped linear systems. Earthq Eng Struct Dyn 14:217-243

Wanitkorkul A, Filiatrault A (2008) Influence of passive supplemental damping systems on structural and nonstructural seismic fragilities of a steel building. Eng Struct 30:675-682

Whittaker AS, Constantinou MC, Ramirez OM et al (2003) Equivalent lateral force and modal analysis procedures of the 2000 NEHRP provisions for buildings with damping systems. Earthq Spectra 19:959-980 